\title{
A Preliminary Study of Knowledge, Attitude and Practices of Pesticide Use Among Oil Palm Workers in Johor
}

\author{
S.N. Marina Mior ${ }^{1,2, *}$, A.M Leman ${ }^{1}$, M.R. Baharudin ${ }^{3}$, R. Masripan ${ }^{1}$, M. Faazir T. ${ }^{2}$, M. Ifwat \\ A. ${ }^{2}$ \\ ${ }^{1}$ Faculty of Engineering Technology, Universiti Tun Hussein Onn Malaysia (UTHM),Parit Raja, Batu \\ Pahat, 86400 Johor, Malaysia. \\ ${ }^{2}$ National Institute of Occupational Safety and Health (NIOSH), Lot 1, Jalan 15/1, Section 15, 43650 \\ Bandar Baru Bangi, Selangor, Malaysia \\ ${ }^{3}$ Faculty of Medicine and Health Science, Universiti Putra Malaysia,43400, UPM Serdang, Selangor, \\ Malaysia.
}

\begin{abstract}
Agricultural sector is a fundamental activity that has been practiced since the civilization of Babylonian, which also has been proven by the glory of Nile River Valley and Mekong Valley. History has shown that the migration of investors and foreign labors in Malaysia in 1960 was to be harvested fortune from the land due to its fertility and suitability. As a developing country, agriculture is one of the important sectors in Malaysia that contributes towards the national economy development. The mentioned sector has indirectly provided benefits both local and global perspectives either in terms of business opportunity as well as employment opportunity. In general, this study aims to assess the level of knowledge, practices and attitudes in the use of pesticides in oil palm plantation workers in Johor. The findings of this study will be used as reference in the farming industry, particularly for the awareness and understanding of good farm management practices and safety for agricultural workers by providing information regarding precautionary measures. This study will engage oil palm workers in Johor which are tasked to carry out pesticides handling activities. A total of 138 respondents were selected for the study. The methodology approaches that will be used in this study are questionnaire and interview. The results of this study will be used as reference in the farming industry, particularly the awareness and understanding of good farm management practices and safety for agricultural Workers By Informing Them Of A Precautionary Measure.
\end{abstract}

\section{Introduction}

As a developing country, agriculture is one of the important sectors in Malaysia that contributes towards the national economy development. The mentioned sector has

* Corresponding author: nazhatulmarina@gmail.com 
indirectly provided benefits both local and global perspectives either in terms of business opportunity as well as employment opportunity. Based on an economic census of the plantation in 2011 by the Department of Statistics Malaysia, there is a total of 390,708 workers in the agricultural sector, which experiencing a growth of $8.5 \%$ since 2005 , and the employment of oil palm plantations alone consists of the total of 300,465 workers to cover 4,960,853 million hectares [1].

According to [2], the plantation area of oil palm and rubber were $86 \%$ of the whole main plantation area all over Malaysia in the year 2000. Due to the rubber price volatility, the plantation of oil palm has dominated the agricultural sector in order to replace most of the rubber plantations, supported by a wide range of purposes that can be exploited from oil palm to generate innovative products. Moreover, Johor has been identified as the state with the highest public workers in the oil palm plantation sector in Peninsular Malaysia. This scenario definitely demonstrates the major contribution of oil palm plantation industry towards the economic growth.

Agriculture is one of the earliest professions practiced and involves a unique system of works. This sector involves extensive use of operating techniques ranging from conventional processes to the application of modern and complex technologies. [3] stated that the working conditions in a country, whether developed or developing, will vary depending on the methods of work. Therefore, the development in these agricultural activities that carried out by the workers has created many risks to human health, and one of them is caused by chemical hazard existed from the uses of various types of insecticides or pesticides. Based on the statistics disclosed by the Department of Occupational Safety and Health (DOSH) in the year of 1991, the agriculture industry is recorded with the second highest reported occurrence of accidents among all sectors of the occupation industry. In 1990, World Health Organization (WHO) which based in Geneva explained that most of the pesticide is a chemical used in agriculture sector to control insects and weeds to assist in increasing the production of crops. The consumed organic products nowadays which potentially contain the excess of several different pesticides might be the cause of the illness. Latest investigation has discovered that a moderate to low awareness among farm workers towards the utilization of pesticide residue in soil, in the air, on plants and in groundwater [4].

In Peninsular Malaysia, there are approximately 4.3 million farmers are located all over 1.5 million hectares of rubber plantations and 0.6 million hectares of oil palm plantations. This amount does not include other agricultural areas that were also using pesticides. In 1991, a report released by the Department of Plant and Machinery Malaysia, which act as the body that implements the Occupational Safety and Health, has shown the accident occurrence rate from improper use of pesticides are four times higher than the accidents that occur in other industries. Therefore this study is planned to be conducted to determine the knowledge, attitudes and practices on the use of pesticides among oil palm plantation workers in the state of Johor.

\section{Literature review}

In Southeast Asia, the countries have improved agriculture from traditional rice cultivation into a more complex market oriented crop cultivation to meet the demands. Therefore, the agriculture activities as well as land area keep increasing and providing job opportunities, economic growth and varieties crop production [5]. According to Sime Darby, Oil World announced that palm oil was the highest type of oil consumed in 2011 [6]. In Malaysia, specifically for oil palm plantations, chlorpyrifors, a type of pesticide was widely used in 
order to reduce the population of bagworms, ceterpillars and rhinoceros beetles that may attack the plantations [7].

A record in 2011 stated that there are 426 palm oil mills in Malaysia with the capacity of processing 99.85 million tonnes of Fresh Fruit Bunches (FFB) annually. Indonesia and Malaysia altogether account for $85 \%$ of global oil palm production covering almost 15 million hectares in 2009. Palm oil is derived from the plant's fruit, which produces two types of oils: crude palm oil (CPO), which comes from the mesocarp of the fruit, and palm kernel oil, which comes from the seed in the fruit. Most CPO is used for food products, while most palm kernel oil is used in non-edible products such as detergents, cosmetics, plastics, as well as a broad range of other industrial and agricultural chemicals [8].

Instead of pesticide usage, Integrated Pest Management (IPM) relies on barn owls or snake to reduce rat populations are an excellent idea and need to be implemented widely [9]. 70\% of Indian population rely on agricultural activity [10] as the emphasis was given highly in agriculture after the green revolution happened. The concerning factor is that Indian farmers apply pesticides according to the pre-determined calender rather than applying based on the requirement basis. A study conducted in Ubon Ratchani, a district in Thailand, found out that Parkinson Disease patients was recorded through their background working history as farmers, who were exposed to paraquat, organo-chlorines as well as other pesticides [11].

Farmers use highly hazardous-monochrotofos, carbofuran and methidation, while $11.11 \%$ of farmers still use PIC(Prior To Inform) pesticides which is prohibited [12]. 61\% of the Indonesian farmers also endured minor poisonings while $14.4 \%$ suffered major poisonings symptoms [13]. A survey conducted in Malaysia shows that $14.5 \%$ of farmers in Cameron Highlands had symptoms of pesticide poisoning [6]. The most common improper usages of pesticides are the usage of extra volumes or concentrations therefore lead to the probability of pesticide exposure. They also preferred to create their own pesticides by mixing several pesticides together hesitated referring to the proper usage and label rate guideline [14].

In Malaysia, Heavy metal industries and pesticides usage caused devastating impacts but was regarded insignificant on the environment [6]. A study by [15] reported that the majority of the farmers, $86 \%$ of them was using pesticides; therefore only $14 \%$ of farmers were not using the pesticides. $31.38 \%$ of pesticides users knows the name of the pesticide they used, that is Foliden, DAP bio bullet for instances. Therefore, $68.62 \%$ of pesticide users did not know even the name of their pesticide they used. A Similar study was conducted in rural areas of Ahmednagar of India revealed, 50\% of the respondents stored the pesticide in the field at the farmhouse, and 20\% at home. In Western Uttar Pradesh and Ahmednagar showed majority $34 \%$ of respondent had used mask/hand gloves and $81 \%$ were using mask followed by $67 \%$ who used gloves [16].

In Malaysia, in order to reduce the usage and application of rodenticides and pesticides, Integrated Pest Management (IPM) with the biological control would be very useful. Using barn owls for instance, yet the cost and efficiency is not that easy to be determined though biological solution will be very environmental-friendly method. Above all, Malaysia government has been very committed in providing good safety workplace condition [17].

\section{Methodology}

Simple random technique will be used in selecting the respondents among the farm workers. The data will be collected in December 2014 using structured questionnaires. The questionnaires will be provided in dual languages, Bahasa Malaysia and English Language to overcome communication issue. The questionnaire contained four sections. The first 
section consists of demographic information, the second section of the questionnaire consists of knowledge related questions, the following section of the questionnaire consists of practice related questions and the final section was designed to assess participant's attitude of farm workers. The questionnaire adapted from Skim Amalan Ladang Baik (SLAM). The sample size of the respondents (n) is about 217 agricultural farm workers (oil palm plantation in Johor) based on the Ministry of Plantation Industry and Commodity Malaysia database. The data will be analyzed using SPSS version 20.

$$
\mathrm{n}=\frac{\mathrm{z}(\mathrm{P}-(1-\mathrm{P}))}{\mathrm{d}}
$$

where,

$$
\begin{aligned}
\mathrm{z} & =95 \% \text { confidence interval } \\
P & =\text { anticipated population proportion }(90 \%) \quad(\text { M.M Yassin et. All) } \\
d & =\text { absolute precision }( \pm 5 \%) \\
& =217 \text { farm workers }
\end{aligned}
$$

\section{Result And Discussion}

The totals of 217 oil palm workers in Johor were given a set of questionnaire. We narrow down our research from 217 respondents to 132 respondents as we intended to investigate a better target group which hands on directly handle the pesticide. The amounts of 132 respondents are obtained from Part A: Demoghraphy Analysis question number 14. By the data obtained from the respondents, the total Knowledge, Attitude, and Practice (KAP) score for each respondent are counted by comparing to the answer scheme provided that had been synchronized to the Skim Amalan Ladang Malaysia (SALM). SALM is a national programmed made by the Ministry of Agriculture Malaysia, MoA, to recognize and certify farms that are engaged in commercial fruits and vegetables production, which adopt agricultural practices that are environmentally-friendly, sensitive to workers' welfare, and yield quality products that are safe for consumption. However, this programme was revised in 2005. Furthermore, SALM-certified farms are entitled to use the "Malaysia Best" logo, which provides an opportunity to brand products in the marketplace [6].

Referring to a journal written by [6], he classified the score into High, Fair Practice and Poor into the range of scores as described in Table 1. The total score for each Knowledge, Attitude, and Practice (KAP) for each 132 respondents are totaled as well as their total score. If the score is more than $80 \%$ of the total question, it is classified as high score, while a score between $80 \%$ and $50 \%$ is classified as fair practice, while a score below $50 \%$ is classified as poor.

The high or good level is highlighted with green colour, while the intermediate or fair practice is highlighted with yellow colour, and the one that is highlighted in red colour, indicating the poor level of score in each component.

Table 1. Average Mark for Each KAP and Total Mark of Respondents.

\begin{tabular}{|c|c|c|c|c|c|}
\hline Total & Score Description & Knowledge & Attitude & Practice & Kap_Overall \\
\hline High & TOTAL $>80 \%$ & 32 & 66 & 101 & 54 \\
\hline $\begin{array}{c}\text { Fair } \\
\text { Practice }\end{array}$ & $50 \%<$ TOTAL $<80 \%$ & 96 & 64 & 30 & 78 \\
\hline Poor & TOTAL $<50 \%$ & 4 & 2 & 1 & 0 \\
\hline & & 132 & 132 & 132 & 132 \\
\hline
\end{tabular}


In Table 1, in the Knowledge Column, the number of respondents who scored more than $80 \%$ is 32 respondents out of 132 respondents, while 96 respondents scored between $50 \%$ to $80 \%$ and there are 4 people who scored below 50\%. For Attitude Column, the number of respondents who scored more than $80 \%$ is 66 respondents out of 132 respondents, while 64 respondents scored between $50 \%$ to $80 \%$ and there are 2 people who scored below $50 \%$. For Practice Column, the number of respondents who scored more than $80 \%$ is 101 respondents out of 30 respondents, while 64 respondents scored between $50 \%$ to $80 \%$ and there are 1 person who scored below $50 \%$.

In Figure 1, we may observe that only $24 \%$ of respondents are in good score, i.e. more than $80 \%$, while $73 \%$ of them are in the intermediate class and $3 \%$ of them are in poor class. Therefore, most of them are in intermediate class and resulting the average mark for knowledge is in intermediate class with a score range between 50\%-80 \%. In Figure 2, specifically $50 \%$ of the respondents scored more than $80 \%$. For intermediate class, of range of score $50-80 \%$, there are $48 \%$ of respondents score in this range while $2 \%$ of respondents score at the poor level.

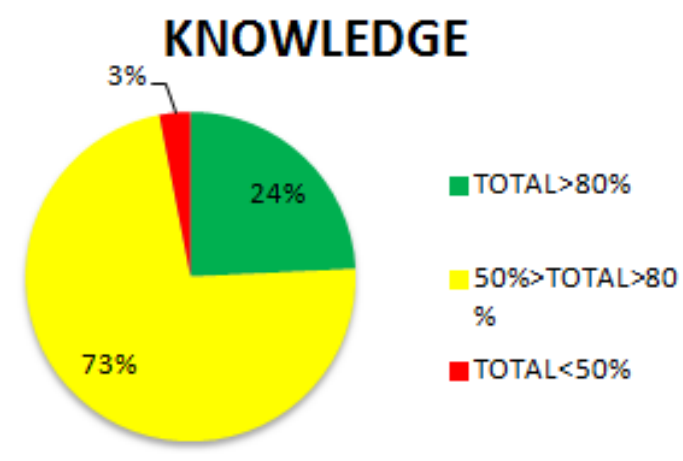

Fig. 1. The Percentage of Knowledge.

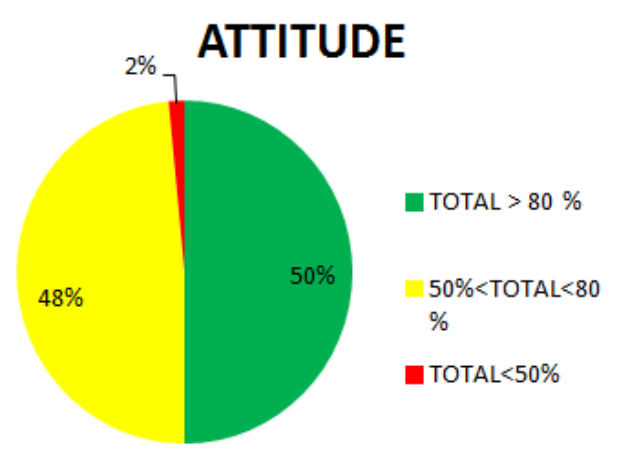

Fig. 2. The Percentage of Attitude.

In Figure 3, the figure shows that there are $76 \%$ of respondents scored more than $80 \%$ in practice part, and for intermediate level, there are $23 \%$ of respondents score between $50 \%$ to $80 \%$, while just $1 \%$ out of 132 respondents scored less than $50 \%$. As the majority of 
them scored at a good level (highlighted green) in the pie chart, therefore the average of practice is more than $80 \%$.

After the scored has been calculated for each of 132 respondents, the total score of each respondent is calculated shown in Figure 4. It was found that only $41 \%$ of respondents fall in the good range with a score of more than $80 \%$ of total question in the questionnaire, while $59 \%$ is in the intermediate level and gladly, no respondent falls in the range of poor level, with scores less than $50 \%$. This is the inference of the average total score falls in the range of $50-80 \%$, as most of the respondents are in the intermediate score.

\section{PRACTICE}

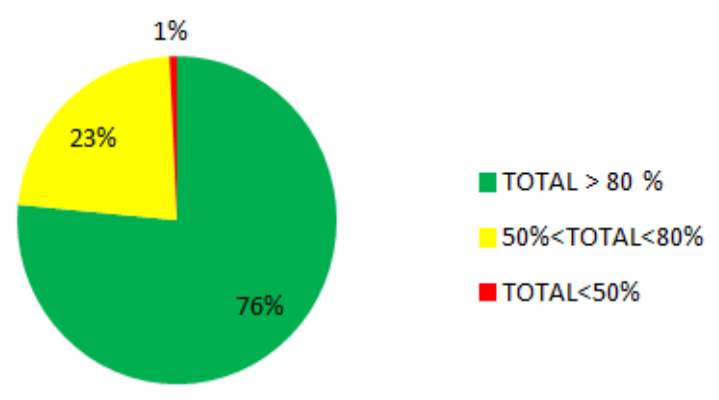

Fig. 3. The Percentage of Practice.

\section{KAP_OVERALL}

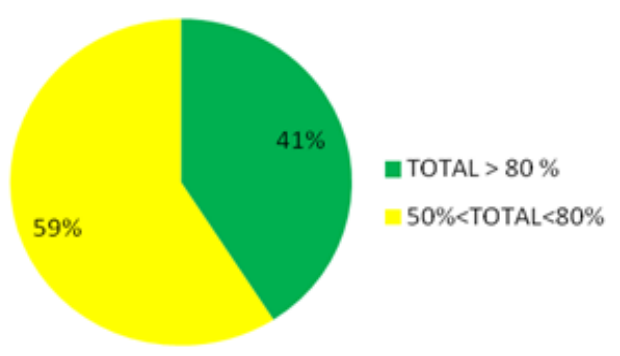

Fig. 4. The Percentage of Overall KAP.

\section{Conclusion}

By observing Table 1 and Table 2, as well as Figure 1, Figure 2 and Figure 3, we may observe that almost $25 \%$ score good in knowledge, $50 \%$ in attitude and almost $75 \%$ score good in practice component. This captured the attention that palm oil workers has low in knowledge, intermediately good in attitude, but surprisingly excellent in practice of handling pesticide sprayers in palm oil plantations in Johor. By the data obtained from demography analysis, as most of the respondents' age ranges from 18-35 years old, therefore they have more years to involve in agricultural activities and are prone to 
determine the agricultural safety and health at workplace. Therefore, more impact knowledge-focused programs need to be arranged and implemented to inculcate the better awareness of pesticides among palm oil workers, as without knowledge, people may become less careful and therefore are exposed to pesticide poisoning and other long term exposure illness in the future.

The authors would like to thank NIOSH for grant funding. Faculty of Engineering Technology, Universiti Tun Hussein Onn Malaysia (UTHM) and Centre for Graduate Studies - UTHM.

\section{References}

1. Garis Panduan Keselamatan dan Kesihatan Pekerjaan Dalam Pertanian, Department of Occupational and Health Malaysia (DOSH), 2011

2. J.K. Mohamad Khan, M. Munauwar, A.A. Fadzli Shah, A. Hassan, Universiti Utara Malaysia, 2002.

3. V. Forastieri, The International Labour Organization (ILO) Programme on Occupational Safety and Health in Agriculture, ILO, Geneva, (1999)

4. J.M. Safi, Egyptian journal occupational Medicine, 19, 267 (1995)

5. J. Chalermphol, G.B. Bastakoti, R.C. Bastakoti, Procedia Environmental Sciences, 20, 418 (2014)

6. S. Bahri, Occupational safety and health in Commodity Agriculture: Case Studies From Malaysian Agricultural Perspective, (2014)

7. H. Muhamad, B.H. Zainudin, N.K. Abu Bakar, Food Chemistry, 134(4), 2489 (2012)

8. J. Janick, History of Agricultural and Horticultural Technology in Asia. Purdue University, 1 (2013)

9. I. Comte, F. Colin, J.K. Whalen, O. Grunberger, J.P. Caliman, Advances in Agronomy, 116, (2012)

10. M.G.C. Yuantari, C.A.M. Van Gestel, N.M. Van Straalen, B. Widianarko, H.R. Sunoko, M.N. Shobib, Environmental Monitoring and Assessment, 187(3), 142 (2015)

11. S. Norkaew, S. Lertmaharit, W. Wilaiwan, W. Siriwong, M.G. Robson, Roczniki Panstwowego Zakladu Higieny, 66(1), 21 (2015)

12. ISBN 924156139 4, World Health Organization (1990)

13. F. Hidayat, T. Khamidi, S. Wiyono, Jurnal Bumi Lestari, 10(1), 1 (2010)

14. N. Taneepanichskul, S. Norkaew, W. Siriwong, Roczniki Panstwowego Zakladu Higieny, 65(4), 291 (2014)

15. D. Neupane, E. Jors, L. Brandt, Environmental Health, 13(1), 1 (2014)

16. R. Ranjan, K. Neupane, A.S. Wantamutte, B. Banjade, N. Kushwaha, R. Neupane, (2014). International Journal of Interdisciplinary and Multidisciplinary Studies, 1(5), 202 (2014)

17. H. Zulkifli, M. Halimah, K.W. Chan, Y.M. Choo, W. Mohd Basri, Journal of Oil Palm Research, 22, 887 (2010) 